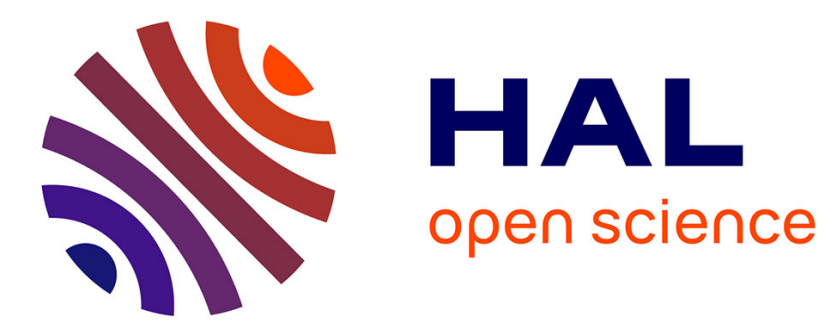

\title{
Contamination levels of human pharmaceutical compounds in French surface and drinking water.
}

S. Mompelat, Olivier Thomas, Barbara Le Bot

\section{To cite this version:}

S. Mompelat, Olivier Thomas, Barbara Le Bot. Contamination levels of human pharmaceutical compounds in French surface and drinking water.. Journal of Environmental Monitoring, 2011, 13 (10), pp.2929-39. 10.1039/c1em10335k . hal-00878545

\section{HAL Id: hal-00878545 \\ https://hal.science/hal-00878545}

Submitted on 30 Oct 2013

HAL is a multi-disciplinary open access archive for the deposit and dissemination of scientific research documents, whether they are published or not. The documents may come from teaching and research institutions in France or abroad, or from public or private research centers.
L'archive ouverte pluridisciplinaire HAL, est destinée au dépôt et à la diffusion de documents scientifiques de niveau recherche, publiés ou non, émanant des établissements d'enseignement et de recherche français ou étrangers, des laboratoires publics ou privés. 


\title{
Environmental \\ Monitoring
}

Cite this: J. Environ. Monit., 2011, 13, 2929

www.rsc.org/jem

PAPER

\section{Contamination levels of human pharmaceutical compounds in French surface and drinking water $\dagger$}

\author{
S. Mompelat, O. Thomas and B. Le Bot* \\ Received 18th April 2011, Accepted 11th July 2011 \\ DOI: 10.1039/c1em10335k
}

\begin{abstract}
The occurrence of 20 human pharmaceutical compounds and metabolites from 10 representative therapeutic classes was analysed from resource and drinking water in two catchment basins located in north-west France. 98 samples were analysed from 63 stations (surface water and drinking water produced from surface water). Of the 20 human pharmaceutical compounds selected, 16 were quantified in both the surface water and drinking water, with $22 \%$ of the values above the limit of quantification for surface water and $14 \%$ for drinking water). Psychostimulants, non-steroidal antiinflammatory drugs, iodinated contrast media and anxiolytic drugs were the main therapeutic classes of human pharmaceutical compounds detected in the surface water and drinking water. The results for surface water were close to results from previous studies in spite of differences in prescription rates of human pharmaceutical compounds in different countries. The removal rate of human pharmaceutical compounds at 11 water treatment units was also determined. Only caffeine proved to be resistant to drinking water treatment processes (with a minimum rate of $5 \%$ ). Other human pharmaceutical compounds seemed to be removed more efficiently (average elimination rate of over $50 \%$ ) by adsorption onto activated carbon and oxidation/disinfection with ozone or chlorine (not taking account of the disinfection by-products). These results add to the increasing evidence of the occurrence of human pharmaceutical compounds in drinking water that may represent a threat to human beings exposed to a cocktail of human pharmaceutical compounds and related metabolites and by-products in drinking water.
\end{abstract}

\section{Introduction}

Human pharmaceutical compounds (HPCs) are emerging contaminants as their discharge are not (yet) regulated. They are continuously entering the aquatic environment, directly through treated wastewater (TWW) discharge or indirectly by landfill leachates. HPCs are bioactive compounds originally designed

School of Advanced Studies in Public Health (EHESP), Laboratoire d'Etude et de Recherche en Environnement et Sante (LERES), Avenue Professeur Leon Bernard, 35043 Rennes Cedex, France. E-mail: Barbara.Lebot@ehesp.fr; Fax: +332 9902 29; Tel: +3329902 2924 $\dagger$ Electronic supplementary information (ESI) available. See DOI: $10.1039 / \mathrm{clem} 10335 \mathrm{k}$ and prescribed to have a specific biological effect on the human body. Depending on their metabolization, HPCs are excreted from the human body as parent compounds and/or metabolites in urine and/or faeces. Wastewater (WW) treatment is the primary attenuation stage ${ }^{1,2}$ but natural attenuation of HPCs may occur in surface water (SW), by i) dilution of TWW effluents (concentrations measured in $\mu \mathrm{g} \mathrm{L}^{-1}$ ) in natural water (concentrations measured in $\mathrm{ng} \mathrm{L}^{-1}$ ), ii) adsorption onto natural organic matter (suspended matter, colloids, dissolved organic matter) and iii) other reactions such as phototransformation and biodegradation. Nevertheless, many studies have shown the presence of HPCs in natural waters at concentrations of the

\section{Environmental impact}

Pharmaceutical compounds in the drinking water cycle may represent a potential threat to human beings as a few works have demonstrated their effects in mixture on human health. In this study, the occurrence of 20 human pharmaceutical compounds was determined in surface and drinking water in north-west France and their qualitative and quantitative distribution was studied. Their removal rate through 11 water utilities is also discussed. Considering the scarcity of data related to the contamination of human pharmaceutical compounds in drinking water this study provides data for the human health risk assessment related to these substances. 
order of $\mu \mathrm{g} \mathrm{L}^{-1}$ 3-14 $^{-1}$ and a few reported HPCs in drinking water (DW) of the order of $n g \mathrm{~L}^{-1} \cdot \mathbf{8 , 1 5}$

However, in some areas where surface water is the main source of DW, such as Brittany (north-west France) where $80 \%$ of DW is taken from SW, controlling HPCs in DW may be an unavoidable issue for human health risk. ${ }^{16}$ Although DW treatment processes were not originally designed to remove pharmaceutical contamination from DW supplies, removing HPCs could become a necessity. ${ }^{17,18}$

The aim of this study was to determine the occurrence of 20 HPCs and metabolites in SW and DW in two catchments basins in north-west France. It may also provide an insight as to the urban impact and monthly variations in HPCs concentrations in SW besides a greater understanding of the efficiency of existing DW treatment processes to remove HPCs from contaminated SW.

\section{Materials and methods}

\section{Selection of target compounds}

A prioritization approach was proposed for selecting HPCs to be analysed from all those prescribed (around 3000 in France for example). A list of $20 \mathrm{HPCs}$ and metabolites from 10 representative classes (Table 1) was drawn up using the following criteria:

i) Widespread use for human medication in France in terms of therapeutic practices and quantities consumed ${ }^{33-35}$ and the existence of several studies reporting their occurrence in water (Table 1).

ii) HPCs poorly metabolized in the human body or having metabolites known to be weakly biodegradable and physically and chemically stable in the environment. ${ }^{8}$

iii) Suspected toxicity of HPCs or their metabolites (e.g. antineoplastic known for their non-threshold cytotoxic activity). ${ }^{8,36,37}$

iv) Existing standards and analytical feasibility.

\section{Study area and sample collection}

Sampling was carried out in two catchment basins, the Vilaine (length $=218 \mathrm{~km}$, catchment basin area $=10533 \mathrm{~km}^{2}$ ) and the Mayenne (length $=202 \mathrm{~km}$, catchment basin area $=4358 \mathrm{~km}^{2}$ ), together with their tributaries (Fig. 1). The average discharge of the Vilaine and the Mayenne is around $70 \mathrm{~m}^{3} \mathrm{~s}^{-1}$ and $50 \mathrm{~m}^{3} \mathrm{~s}^{-1}$, respectively. $70 \%$ of the DW in the Ille et Vilaine department is taken from SW. The Mayenne river supplies $58 \%$ of the DW in the Mayenne basin.

Samples were taken from 63 stations between January and April 2009. Fig. 1 shows the $31 \mathrm{SW}$ sampling stations (including SW stations and SW from the inlets of some water utility stations) and $43 \mathrm{DW}$ sampling stations (DW samples collected at the outlet of water utility stations).

For some sampling stations, both SW and DW were sampled, giving a total of 98 samples analysed. Depending on the station, SW was sampled from the river, the river bank, a bridge, or a boat. $500 \mathrm{~mL}$ of water was collected using a long handled ladle. For DW, $500 \mathrm{~mL}$ was collected directly at the water treatment plant outlet from the sampling tap connected to the distribution network. Samples were stored into amber glass bottles and transported in an icebox at $5{ }^{\circ} \mathrm{C} \pm 3{ }^{\circ} \mathrm{C}$, and analysed within a maximum of 2 days.

\section{Reactants}

All HPCs standards had $97 \%$ to $99.9 \%$ purity and were purchased from Sigma-Aldrich (Saint Quentin Fallavier, France) except for IOP which was purchased from Cluzeau Info Labo (Sainte Foy La Grande, France). A $1 \mathrm{~g} \mathrm{~L}^{-1}$ stock solution of each HPC was prepared in HPLC grade methanol and stored at $-18{ }^{\circ} \mathrm{C}$ for use within 6 months. HPLC grade formic acid (FA) and 98\% pure ammonium hydroxide were purchased from Carlo Erba (Val de Reuil France) and Fisher Bioblock (Illkirch, France), respectively. HPLC grade acetonitrile (ACN) for ultra performance liquid chromatography ${ }^{\circledR}\left(\mathrm{UPLC}^{\circledR}\right)$ was purchased from J.T Baker (Atlantic Labo ICS, Bruges, France). A 99\% pure standard pesticide (fenuron), used as a tracer to monitor the progress of extraction, was purchased from VWR (Fontenay sous Bois, France). A stock solution of fenuron at $10 \mathrm{mg} \mathrm{L}^{-1}$ was prepared in methanol and stored at low temperature $\left(+4{ }^{\circ} \mathrm{C}\right)$. Purified water was produced using a Milli-Q water system (Millipore, France)

Table 1 Target HPCs found in drinking water worldwide (see references)

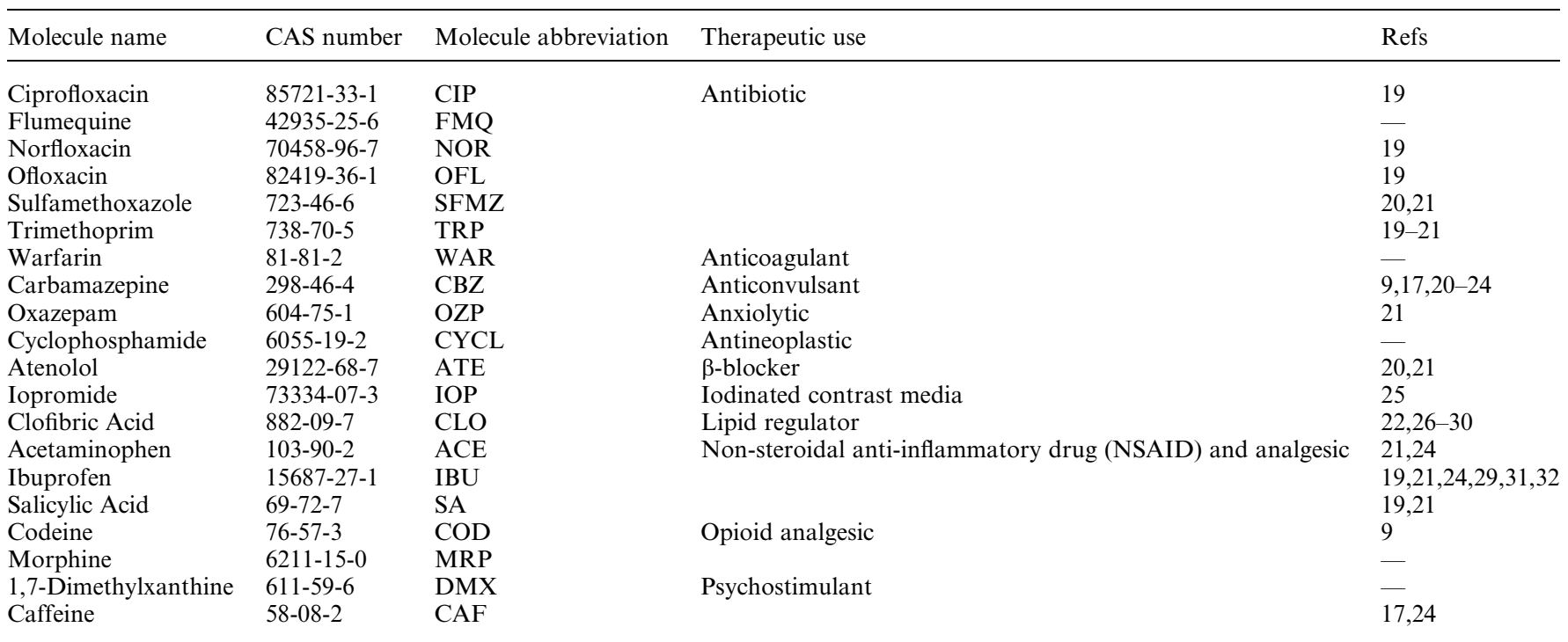




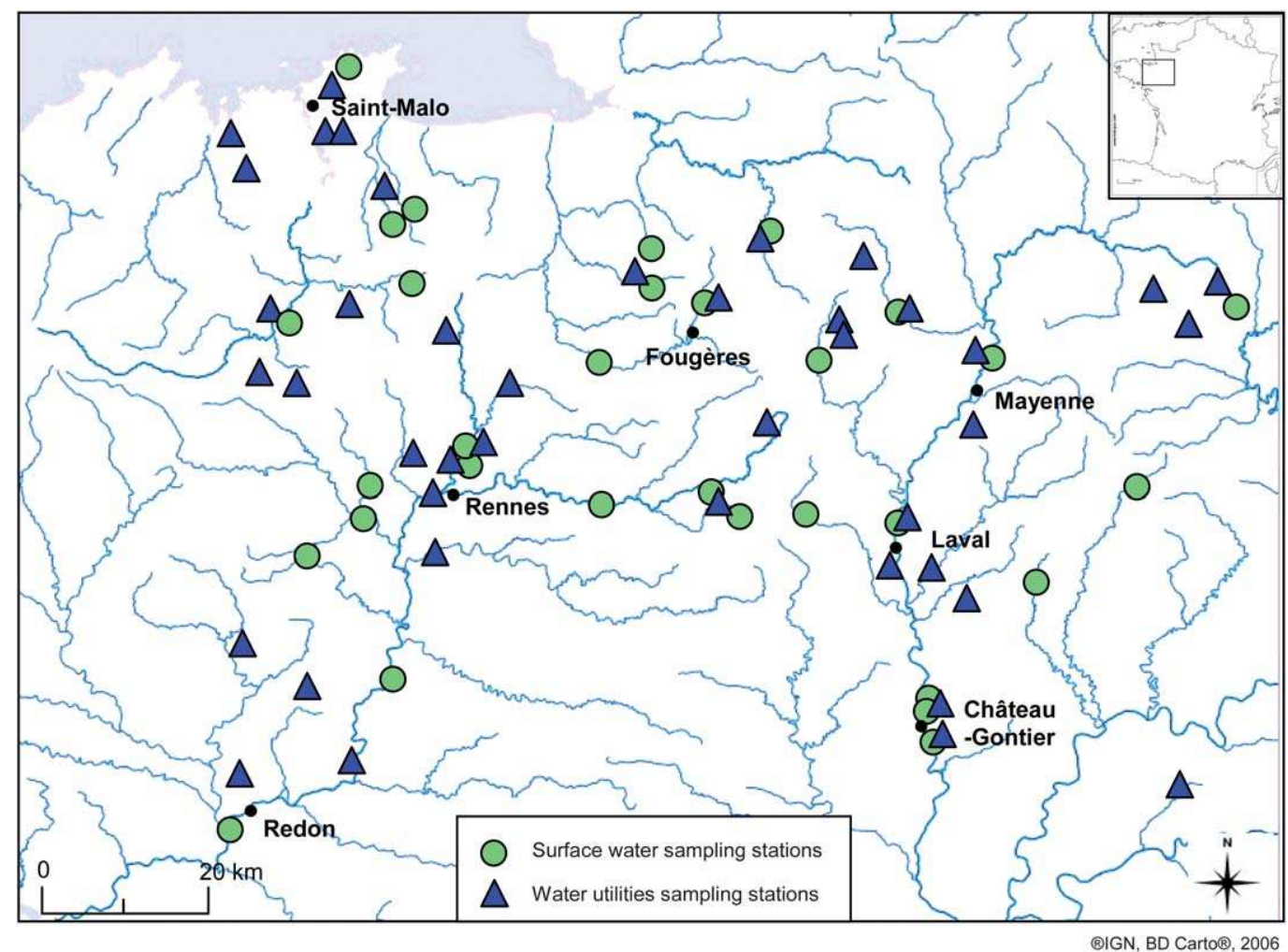

Fig. 1 Sampling stations (SW samples were taken from surface water stations and from some water utilities. DW samples were taken from the outlet of water utilities).

and was used during the chromatographic separation as a solvent in the mobile phase. Mineral water (in a glass bottle - Evian, Cachat source-SAEME, France), was used for calibration and as a blank because of its very stable quality and its medium mineralization (dry residue at $180{ }^{\circ} \mathrm{C}=309 \mathrm{mg} \mathrm{L}^{-1}$ ).

\section{Sample preparation}

$120 \mu \mathrm{L}$ of $20 \mathrm{~g} \mathrm{~L}^{-1}$ sodium nitrite solution was added to the samples immediately upon receipt at the laboratory in order to reduce residual free chlorine. Each homogenized sample $(500 \mathrm{~mL})$ was vacuum-filtered using a $0.7 \mu \mathrm{m}$ glass fiber filter because this study was only focused on the presence of HPCs in the dissolved phase of waters used to produce DW. In order to optimize the solid phase extraction (SPE) step, the $\mathrm{pH}$ was adjusted to 7 using a pure solution of formic acid or ammonium hydroxide. $25 \mu \mathrm{L}$ of fenuron at $10 \mathrm{mg} \mathrm{L}^{-1}$ was added before extraction. The extraction and analytical procedures were adapted from Tamtam et l. $^{38}$ A single extraction-separationdetection procedure was developed for the analysis of the 20 HPCs in SW and DW.

The SPE procedure is widely used for HPCs extraction because it allows efficient extraction of all compounds, whether alkaline or acid, for analysis at concentrations in the order of $n g \mathrm{~L}^{-1}$ in environmental water samples. ${ }^{39}$ Oasis hydrophilic-lipophilic balance (HLB) extraction cartridges $(200 \mathrm{mg}, 6 \mathrm{~mL}$, Waters, Saint-Quentin en Yvelines, France) were used to extract from a $500 \mathrm{~mL}$ sample. SPE of HPCs was performed using an ASPEC XL (automated sample preparation with extraction columns,
Gilson, Villiers-le-Bel, France). Samples were passed through cartridges previously pre-conditioned with $1 \mathrm{~mL}$ of methanol followed by $1 \mathrm{~mL}$ of ultra pure water at a flow rate of $10 \mathrm{~mL}$ $\min ^{-1}$. HPCs were then eluted with $5 \mathrm{~mL}$ of methanol after washing the cartridges with $2 \mathrm{~mL}$ of $5 \%$ methanol in ultra pure water at $2 \mathrm{~mL} \mathrm{~min}^{-1}$, and vacuum-dried for $10 \mathrm{~min}$ under nitrogen gas to remove excess water. The extracts were stored in methanol in a glass tube, at $-4{ }^{\circ} \mathrm{C}$ for a maximum of 2 weeks.

Samples were evaporated under a gentle nitrogen stream until close to dryness and reconstituted with an acidified (0.01\% FA) $5 \%$ solution of $\mathrm{ACN}$ in water to a volume of $0.5 \mathrm{~mL}$, i.e. an enrichment factor of 1000 , and then transferred into screw cap vials with silicone-PTFE (polytetrafluoroethylene) septa from Waters.

\section{UPLC $^{\circledR}$-MS/MS analysis}

Using UPLC ${ }^{\circledast}$ for analysis provides good sensitivity and resolution within a short analysis time. ${ }^{7,38,40-42}$ UPLC $^{\circledR}$ analysis was performed using a Waters Acquity UPLC ${ }^{\circledR}$ system (Waters, St-Quentin-en-Yvelines, France), fitted with a binary gradient module, an autosampler regulated at $+4{ }^{\circ} \mathrm{C}$, and a column oven kept at $+50{ }^{\circ} \mathrm{C}$. The $20 \mathrm{HPC}$ were separated using an Acquity UPLC BEH column $(1.7 \mu \mathrm{m}$ particle size, $100 \times 2.1 \mathrm{~mm}$ i.d., Waters) at a flow rate of $0.5 \mathrm{~mL} \mathrm{~min}{ }^{-1}$. All HPCs were separated in one single gradient run (15 $\mathrm{min})$ using a binary mobile phase. $10 \mu \mathrm{L}$ of the final extract sample in $5 \%$ acetonitrile in water was injected. The mobile phase consisted of an ultrapure water-ACN gradient both acidified with $0.01 \% \mathrm{FA}$. The concentration of 
ACN was held at $5 \%$ for the first 3 min, with a linear gradient to $30 \%$ from 3-9 min, a linear gradient to $95 \%$ from $9-10 \mathrm{~min}$, held at $95 \%$ from $10-12 \mathrm{~min}$ and a linear gradient to $5 \%$ from $12-$ $13 \mathrm{~min}$ (return to initial conditions), held at 5\% from $13-15 \mathrm{~min}$, (re-equilibration time). The retention times for the analytes are listed in Table 2.

The UPLC ${ }^{\circledR}$ system was coupled to a Quattro Micro ${ }^{\mathrm{TM}}$ triple quadrupole mass spectrometer (Waters, St-Quentin-en-Yvelines, France) with an electrospray ionisation (ESI) source with an orthogonal Z-spray ${ }^{\mathrm{TM}}$. HPCs were detected by selected reaction monitoring (SRM) used in positive or negative mode to obtain the best signal for each HPC (see Table 2). Two SRM-transitions $(\mathrm{m} / \mathrm{z}$, mass to charge ratio) were monitored for each HPC (Table 2), except for IBU which has only one $\mathrm{m} / \mathrm{z}$ transition, with a dwell time set of $5 \mathrm{~ms}$ and a time delay of $2 \mathrm{~ms}$. To achieve the highest sensitivity, 7 windows containing between one and six analytes were defined within the $15 \mathrm{~min}$ run analysis. Collision energy $(\mathrm{eV})$, and cone voltage $(\mathrm{V})$ are given in Table 2 . The ESI and desolvation temperatures were $130{ }^{\circ} \mathrm{C}$ and $450{ }^{\circ} \mathrm{C}$ respectively. The capillary voltage was $3 \mathrm{kV}$. The collision gas (argon) was set to $2.510^{-3}$ mbar ( $99.9 \%$ purity, Air Liquide, Paris, France). Nitrogen was used as the cone gas at $50 \mathrm{~L} \mathrm{~h}^{-1}$ and desolvation gas at $650 \mathrm{~L} \mathrm{~h}^{-1}$ (>99.9\% purity, Air Liquide). Mass Lynx V4.1 was used for system control and data processing.

\section{Validation of the analytical protocol}

Precautions were taken to provide satisfactory quality assurance. One blank (mineral water with tracer) was run for each set of extractions. When the concentrations measured in a blank exceeded $10 \%$ of the concentrations measured for the following field samples, the results were eliminated. Calibration curves were obtained by analysing spiked samples. Samples of Evian mineral water were spiked with a standard solution of all the HPCs in methanol at 5 different levels of concentration from 5/10ng $\mathrm{L}^{-1}$ to $500 \mathrm{ng} \mathrm{L}^{-1}$.

Each analyte was identified by i) the retention time compared to a calibration standard and ii) the presence of the 2 SRM transitions with a signal to noise ratio $(S / N)$ greater than 3 .

In addition, an extraction control of $500 \mathrm{~mL}$ of Evian water spiked with all HPCs at $100 \mathrm{ng} \mathrm{L}^{-1}$ was run every 15 samples to check the extraction step efficiency. The recoveries (\%) for each HPCs (see ESI $\dagger$ ) were evaluated for at least 3 replicates in order to have significant results.

When quantification of a HPC presented a difference greater than $20 \%$ between its two SRM transitions, fenuron was also used to correct concentration of concerned HPC. In some cases, when matrix effects were suspected the sample extracts were also diluted to reduce the impact the impact of ionization on quantification. However, standard addition or the use of an isotopelabelled internal standard for each target analyte would ideally be more convenient to avoid the impact of the matrix effect on the quantitative results. A quadratic regression analysis was used to estimate concentrations of HPCs in samples (5 calibration points). Note that for a range from 5 to $200 \mathrm{ng} \mathrm{L}^{-1}$ a linear regression calibration curve can be used for quantification. All coefficients of correlation $\left(R^{2}\right)$ were equal to or greater than 0.95 . Two SRM transitions were considered for HPCs quantification except for Ibruprofen for which only one $\mathrm{m} / \mathrm{z}$ transition was considered for both its identification and quantification. All positive signals were quantified only when $S / N$ was greater than or equal to 5 in each sample according to USFDA guidelines. ${ }^{43}$

The limits of detection (LOD) ranged from 0.3 to $9 \mathrm{ng} \mathrm{L}^{-1}$ and the limits of quantification (LOQ) from 1 to $50 \mathrm{ng} \mathrm{L}^{-1}$ (see $\mathrm{ESI} \dagger$ ).

Table 2 UPLC ${ }^{\circledast / M S} / \mathrm{MS}$ parameters for target HPC

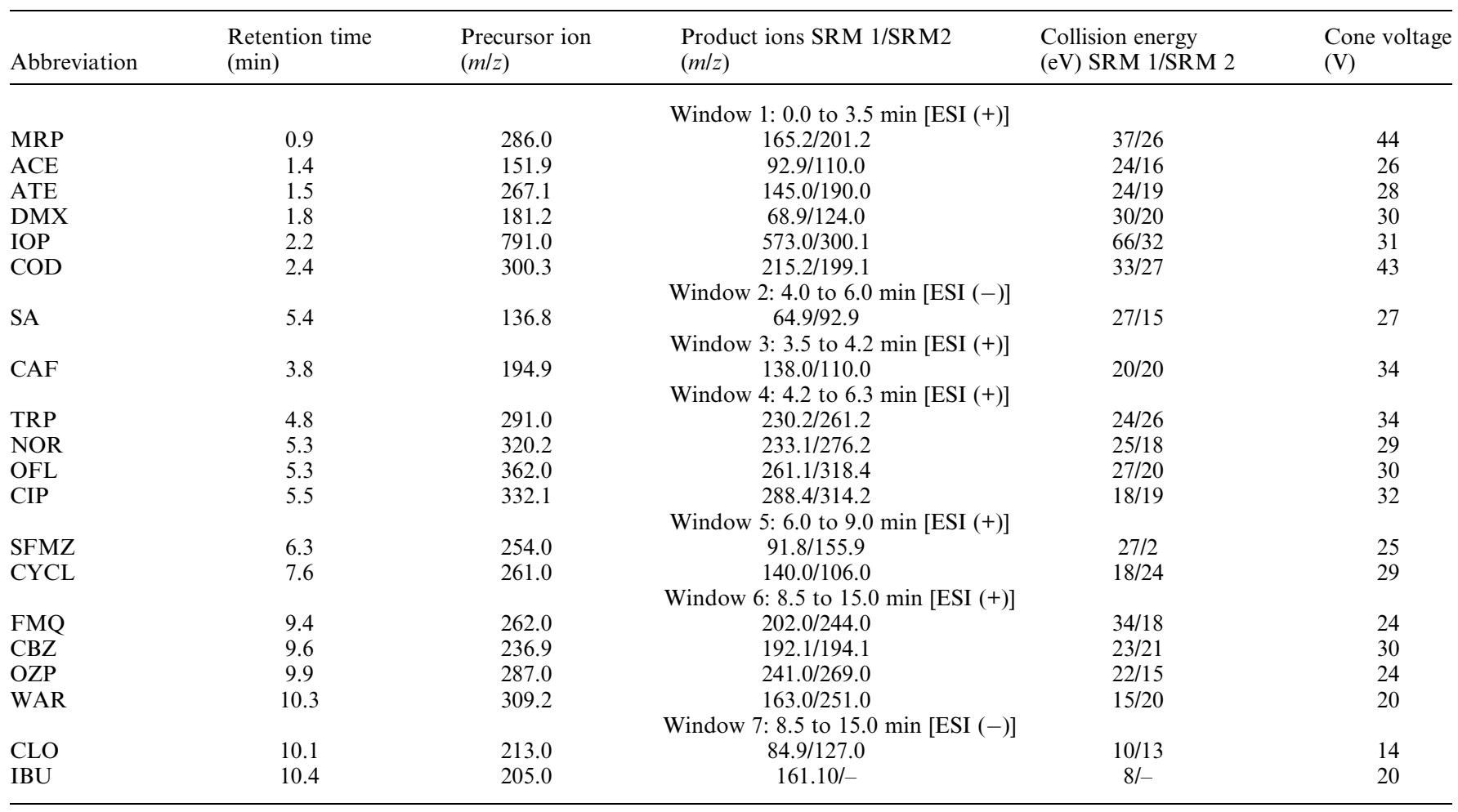


Intra-laboratory reproducibility tests yielded a relative standard deviation (RSD) of up to $27 \%$ in resource water $(n=30)$ and up to $15 \%$ in $\mathrm{DW}(n=25)$. The evaluation of the inter-laboratory performances for the analysis of 4 HPCs, i.e. CBZ, OFL, ATE and ACE, was evaluated during an interlaboratory essay involving 30 laboratories. The individual absolute $z$-score were calculated (according to IUPAC following AOAC and ISO directives) and were comprised between 0 and 1 for all results obtained, showing satisfactory performance of the HPCs analysis method.

\section{Results}

The results are given in the ESI. $\uparrow$ Taking into account the missing data owing to experimental errors during sampling or analytical problems (non validated results), 31\% (604) of the 1960 expected values ( 98 samples $\times 20$ HPCs) were eliminated. Of the validated results, 68\% (920) had concentrations below the LOD, 10\% (138) were between the LOD and the LOQ, and 22\% (294) had concentrations above the LOQ ( $S / N$ ratio greater than 5 for each sample). There was clearly a difference between the SW and DW samples with $86 \%$ of the results (252) above the LOQ for the SW against $14 \%$ (42) for the DW samples.

\section{Concentration distribution}

Fig. $2 \mathrm{a}$ and $2 \mathrm{~b}$ show the HPCs concentrations distribution for SW and DW samples. The range of HPCs concentrations in SW (Fig. 2a), gives three groups of compounds:

- Compounds with high concentrations in SW (ACE, CAF, IOP, CLO, DMX, in decreasing order) up to $300 \mathrm{ng} \mathrm{L}^{-1}$. These results are of the same order as for other works. ${ }^{7,24,25,44}$ Although the maximum concentrations were relatively high, the median values were between 20 and $60 \mathrm{ng} \mathrm{L^{-1 }}$, except for CLO with a lower median.

- Compounds with intermediate concentrations in SW (SA, IBU, and OZP), the maximum concentrations being up to $90 \mathrm{ng}$ $\mathrm{L}^{-1}$. Although IBU was found in only 3 samples, this is consistent with the range of concentrations already found in French and UK surface waters. $^{21,24}$ The median values of these substances were between 20 to $30 \mathrm{ng} \mathrm{L}^{-1}$. OZP comes from directly ingested $\mathrm{OZP}$, as well as other anxiolytic drugs, such as nordiazepam and diazepam. ${ }^{45}$

- 12 compounds with low concentrations, below LOQ or even below LOD (ATE, FMQ, SFMZ, CBZ, COD, OFL, TRP, MRP, NOR, WAR, CIP, CYCL). These compounds had maximum concentrations less than $30 \mathrm{ng} \mathrm{L}^{-1}$ and median values up to $8 \mathrm{ng} \mathrm{L}^{-1}$. Contrary to the results of this study, ATE had previously been reported at concentrations of up to $240 \mathrm{ng}$ $\mathrm{L}^{-1}, 3,7,30,48$ and SFMZ had been found in the river Seine in France in all samples with median concentrations up to $70 \mathrm{ng} \mathrm{\textrm {L } ^ { - 1 }}$. $^{\mathbf{1 0}}$ Furthermore, CIP and CYCL were not detected in all SW samples analysed in our study. It is surprising to note the absence of CIP, the consumption of which is greater than that of OFL. ${ }^{34}$

HPCs concentrations in DW are shown in Fig. 2b, with the same pattern as for SW (three groups of concentrations). In general, there is a significant decrease in the concentrations of most HPCs between SW and DW, which may be attributed to the removal/degradation efficiency of the treatment processes. These results are in accordance with the literature for the occurrence of HPCs in DW (Table 1). Concentrations of HPCs found in DW samples were around two to four times lower than their maximum concentrations in SW (from 300 to $85 \mathrm{ng} \mathrm{L}^{-1}$ for the first group and from 30 to $12.5 \mathrm{ng} \mathrm{L}^{-1}$ for the second group). The HPCs ranking slightly changed between SW and DW samples. However, the maximum concentration of SA was around $100 \mathrm{ng}$ $\mathrm{L}^{-1}$ in both SW and DW and CAF and DMX had the higher concentrations of HPCs in DW.

Two compounds were not found in the DW (MRP and SFMZ) contrary to previous studies which have already reported concentrations of SFMZ in DW. ${ }^{20,21}$ The nature of the treatment processes used in the WUs may explain the difference of removal of SFMZ between the previous studies and the present one. The treatment scheme in all WUs investigated in this study presented steps of clarification, oxidation (by ozone, chlorine or chlorine dioxide), sand and activated carbon filtration, completed by an ultimate disinfection step with chlorine or chlorine dioxide (Table 3). Although in Vulliet et al. ${ }^{21}$ SFMZ was found at $0.8 \mathrm{ng} \mathrm{L}^{-1}$ in one DW sample from a WU which used no oxidation step besides only one single step of filtration before disinfection with chlorine. Similarly, in Benotti et al., ${ }^{20} \mathrm{SFMZ}$ was also found in DW at $3.0 \mathrm{ng} \mathrm{L}^{-1}$. Sulfonamides are known to be more reactive with chlorine or chlorine dioxide than with chloramine. ${ }^{46,47}$ This may be the main reason which would explain why SFMZ was entirely removed after disinfection by chlorine or chlorine dioxide in this study and was found in DW after disinfection with chloramine. Although COD, which together with MRP, is a widely prescribed opioid analgesic, was found in only one DW sample at only $1 \mathrm{ng} \mathrm{L}^{-1}$, it has been reported at $30 \mathrm{ng} \mathrm{L}^{-1}$ in an other study. ${ }^{9}$ The WUs in the present study all presented advanced oxidation processes with ozone for which HPCs are well removed (Table 3). However, there was not such treatment process in the WU investigated in Stackelberg et $a{ }^{9}{ }^{9}$ to remove residual COD.

16 HPCs were found in both SW and DW samples. With the exception of CYCL that was never detected, the other HPCs were present in at least one sample (in SW or DW). Although these results are globally comparable to other studies (Table 1) some differences must be underlined, in particular for NSAIDs.

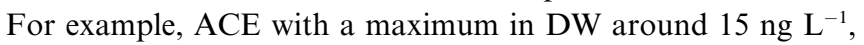
close to the $17 \mathrm{ng} \mathrm{L}^{-1}$ already reported, ${ }^{21}$ has already been found at a concentration of $210 \mathrm{ng} \mathrm{L}^{-1}$ in France. ${ }^{24}$ In other countries, reported concentrations for ACE varied from $8.5 \mathrm{ng} \mathrm{L}^{-1}$ in Finland, ${ }^{31,32}$ to $1350 \mathrm{ng} \mathrm{L}^{-1}$ in USA. ${ }^{31}$

Antibiotics, CIP, NOR and OFL, have already been reported in DW. ${ }^{19}$ However, this may be the first report of FMQ in DW, at low frequency and concentrations under $2 \mathrm{ng} \mathrm{L}^{-1}$.

\section{Therapeutic class distribution assessment}

After considering the occurrence of each individual HPC in SW and DW, it is interesting to show the global relative distribution of HPCs with regard to their therapeutic class by summing the concentrations and dividing by the number of substances per class (Fig. 3). The total amount of HPCs, calculated as the sum of the concentrations of the various classes, was greater than $10 \mu \mathrm{g} \mathrm{L}^{-1}$ for $\mathrm{SW}$, around ten times higher than for DW samples (around $1.2 \mu \mathrm{g} \mathrm{L}^{-1}$ ). The weight of each class was calculated as 

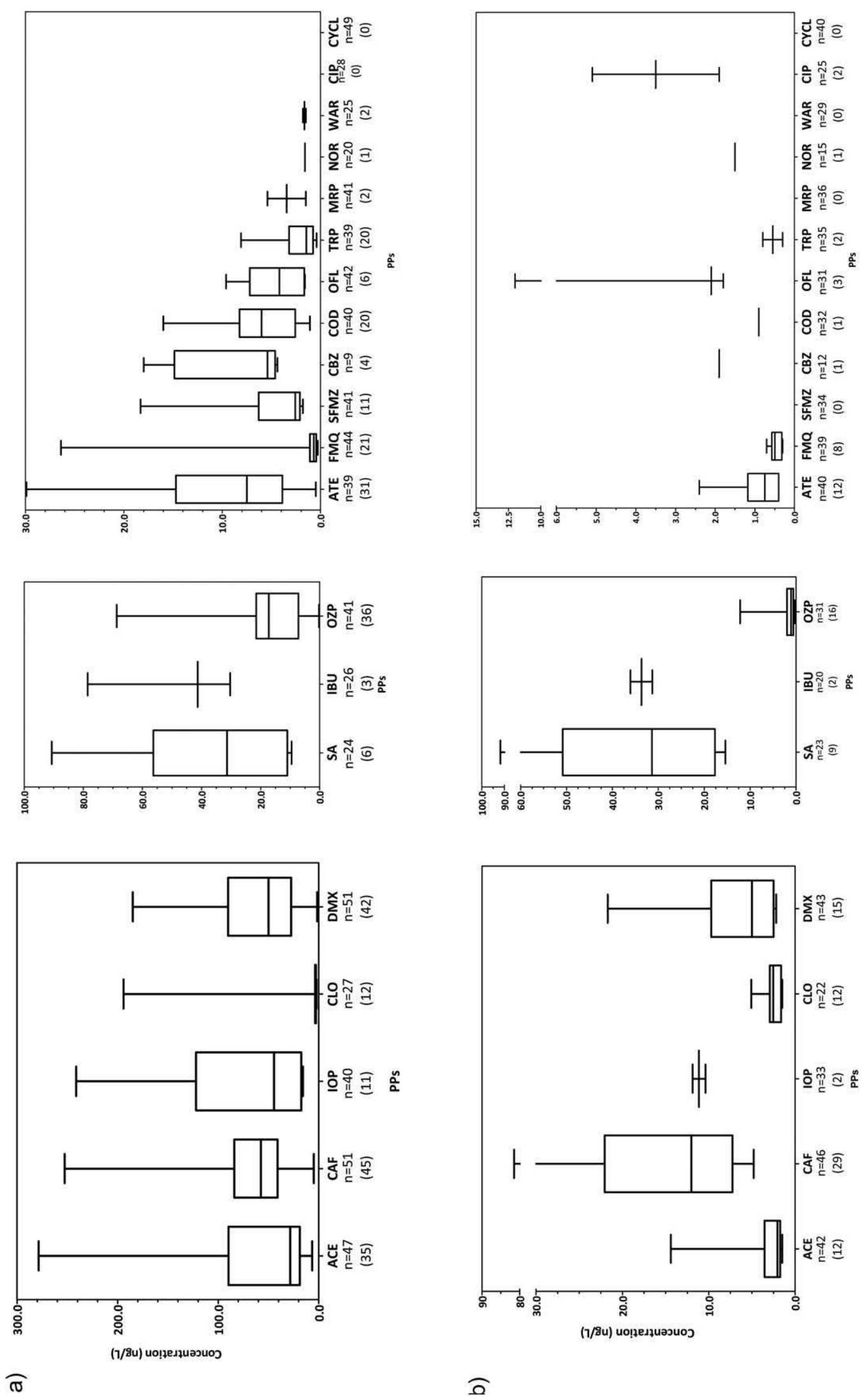

Fig. 2 Individual HPCs concentrations in a) surface water, b) drinking water in north-west France. Box plots 25/75, line at median. 
Table 3 Contents of total organic carbon in SW and DW samples from water utility 1 to water utility $11^{a}$

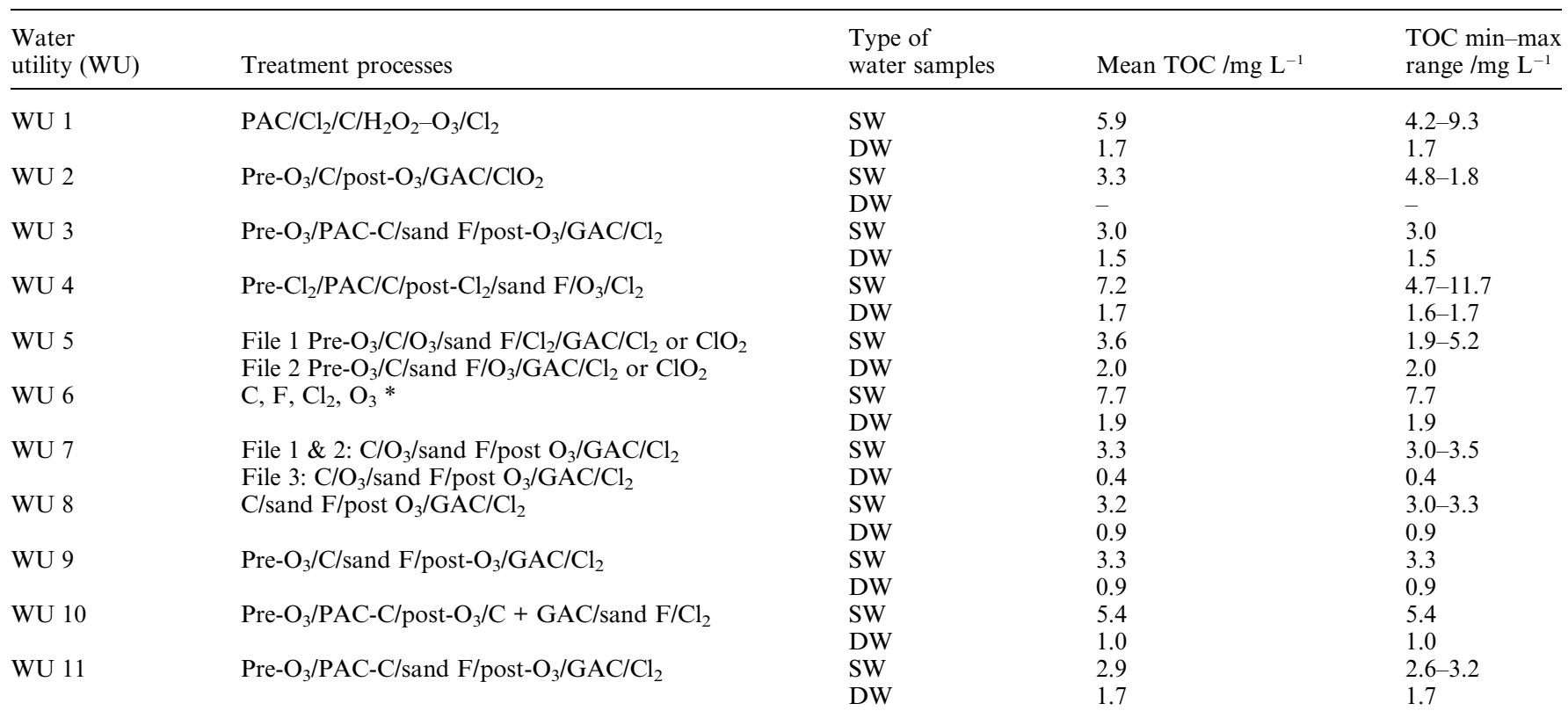

${ }^{a} \mathrm{C}$ : Clarification, $\mathrm{F}$ : filtration, $\mathrm{O}_{3}$ : ozonation, $\mathrm{Cl}_{2}$ : chlorination (hypoclorite), $\mathrm{ClO}_{2}$ : chorine dioxide, GAC: granular activated carbon, $\mathrm{PAC}$ : powdered activated carbon, *(information about the nature of treatment processes are given despite their respective links between each other).

a percentage, by dividing the global concentration of a class by the total amount of HPCs.

Psychostimulants, CAF and its main metabolite, DMX, was the main family with $48 \%$ in SW and $54 \%$ in DW. The ubiquitous presence of CAF and DMX (resistant to waste and drinkingwater treatment processes) is consistent with previous studies, ${ }^{24,49,50,51}$ some of which suggest considering CAF as a possible marker of anthropogenic pollution.

Regarding the distribution of the remaining therapeutic classes of HPCs in SW, (grey pie-chart in Fig. 3a), the top 5 are: 1) NSAIDs and iodinated contrast media (ICM) (28\%), 3) anxiolytic drugs $(20 \%)$, 4) $\beta$-blockers $(10 \%)$ and 5) lipid regulators $(8 \%)$. The distribution of other classes of less than $4 \%$ (and even $0 \%$ for antineoplastics that were not detected) can be explained by the low administration dose, the partial excretion rates in urine and natural attenuation (mainly through dilution, biodegradation and photodegradation). ${ }^{34,36,52}$ A comparison with consumption data shows that the NSAIDs ranking is coherent, ACE being for example the most common drug consumed in France in 2008. ${ }^{33,34}$ However, the results for antibiotics are not consistent with their consumption as exclusively human drugs (CIP, OFL, NOR), or as both human and veterinary drugs (SFMZ, TRP, FMQ). ${ }^{53,54}$ This result points out the potential impact of the attenuation of antibiotics from their release into the environment to natural waters. Fluoroquinolones and sulfonamides may be subject to sorption on natural organic matter from sewage sludge, suspended matter in water, soil and sediments. ${ }^{8,55-57}$ Antibiotics may also potentially be transformed in the environment by direct or indirect photolysis, and biodegradation. ${ }^{57,58}$

The difference in the weight of HPCs in SW and DW was mainly for NSAIDs, being $28 \%$ in SW and $60 \%$ in DW, owing to their resistance to DW treatment processes. The four other therapeutic classes representing the major contribution of HPC contamination in DW were lipid regulators and anxiolytic drugs, ICM and $\beta$-blockers.

\section{Drinking water treatment efficiency}

The drinking water treatment efficiency was assessed using data for 11 water treatment plants or water utilities (WUs) (WU 1 to 11, Table 3) for which SW and DW samples were analysed. The removal efficiencies could only be calculated for samples less than one day old. For WUs fed from several surface sources, a weighted SW concentration was calculated from the feed flows and the corresponding HPC data. The removal efficiency was considered only if 3 results were available for a given HPC (12 HPCs concerned, raw data presented in ESI $\dagger$ ).

In parallel, the total organic carbon (TOC) was also measured (Table 3 ) in the corresponding SW and DW samples, showing a mean removal yield of $67 \% \pm 16 \%$.

The studied WUs used various processes for producing drinking water, all of which included two types of treatment (Table 3). The first group of processes was based on elimination by retention, with clarification (coagulation, flocculation and sedimentation), powder activated carbon (PAC) or granular activated carbon (GAC) filtration, and sand filtration. The second group included transformation by degradation processes such as pre-, intermediate and post- oxidation with ozone $\mathrm{O}_{3}$ and/or chlorine, and disinfection by chlorination. The choice of treatment processes for the WUs depends on the vulnerability of the DW resources (surface water in rural areas).

Studying the retention/degradation rate of the $20 \mathrm{HPCs}$ through the 11 WUs of the study revealed four groups: 
a)
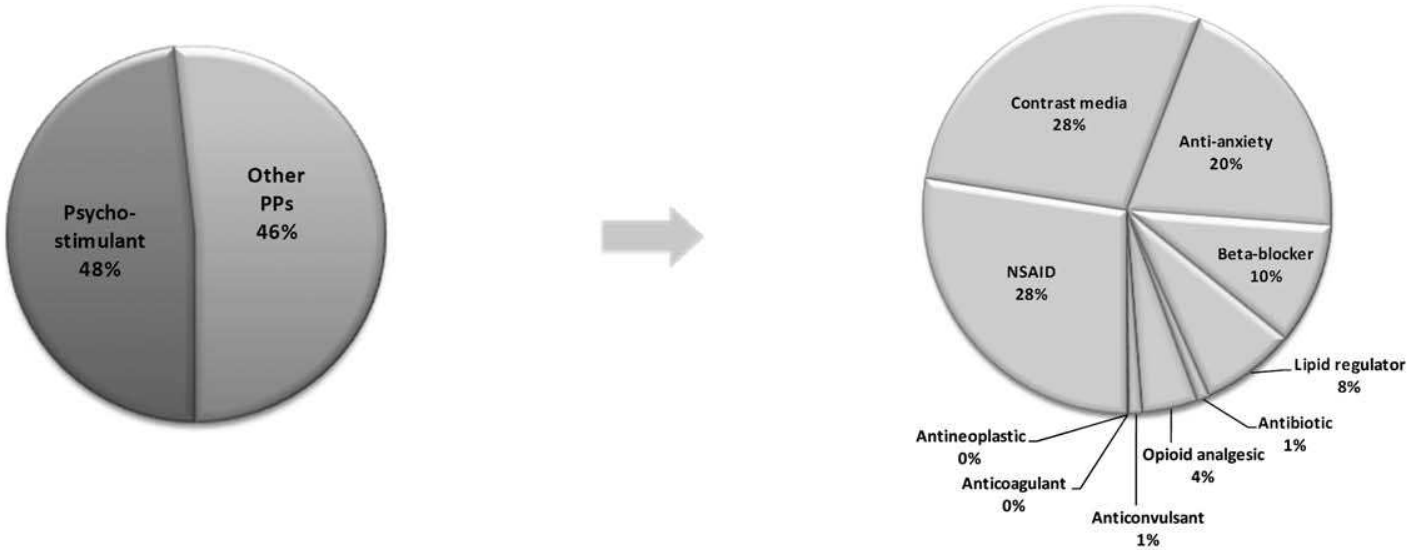

b)
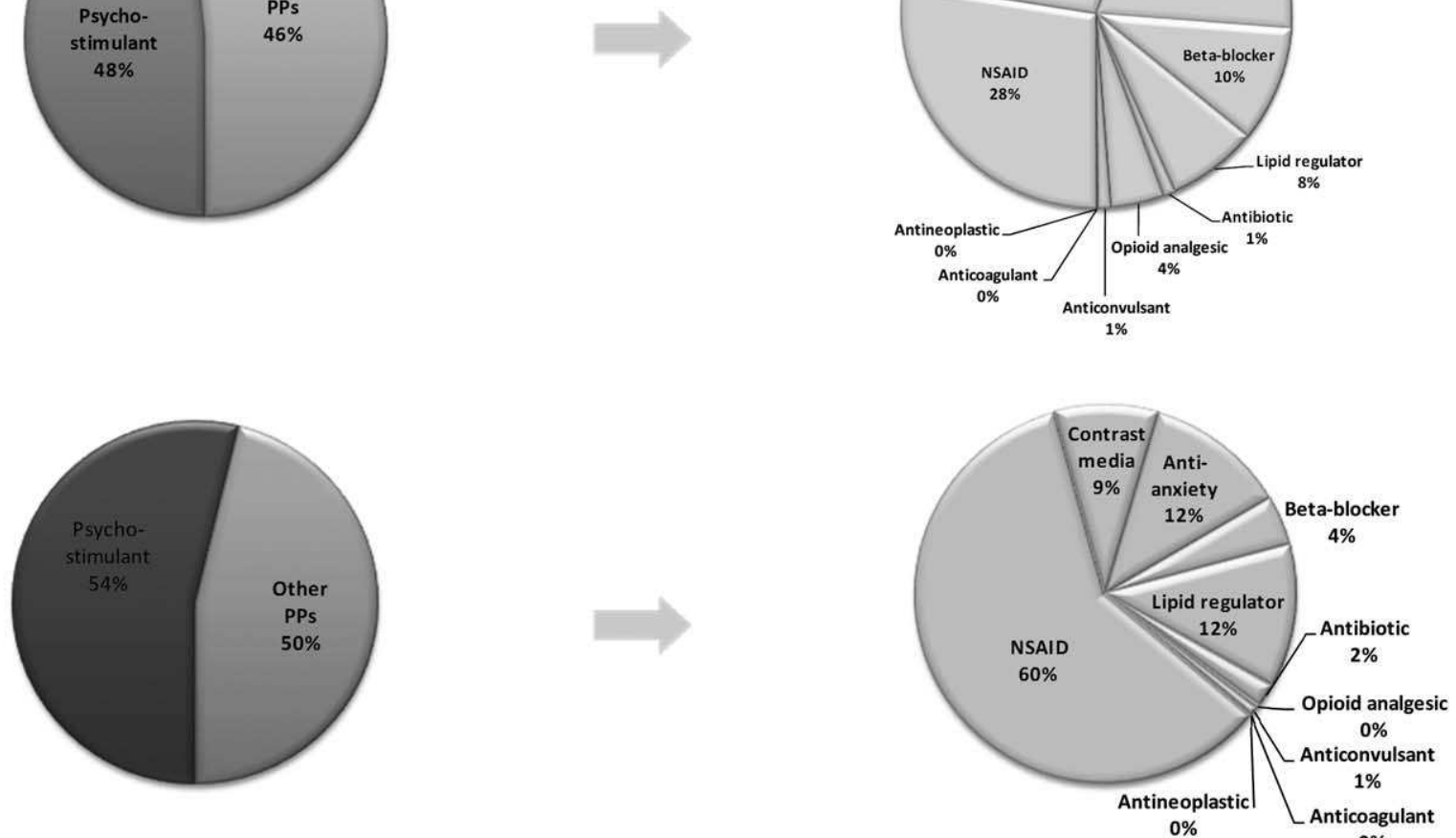

$0 \%$

Fig. 3 Quantitative distribution of HPCs in a) surface water, b) drinking water.

- NOR, TRP, WAR, CBZ, IBU and COD seemed to be totally removed;

- OZP, ATE, IOP, ACE, SA, CAF and DMX were partially removed with efficiencies ranging from $70 \%$ for IOP to $96 \%$ for DMX;

- CIP, FMQ and CLO were only present in DW at very low concentrations;

- OFL, SFMZ, CYCL and MRP were not found in SW and DW.

The average efficiency rate of HPC removal in the 11 WUs was always greater than $90 \%$ with 6 between 90 and $95 \%$ and 5 greater than $95 \%$. WU 4 (Table 3) with relatively high TOC concentrations (up to $11.7 \mathrm{mg} \mathrm{L}^{-1}$ ) has the lowest removal rate (88\%), average of 2 samplings.

These results must be treated with caution because some values were eliminated (not validated) and, as samples were collected as spot samples, the variability of the water quality over a period was not taken into account.

\section{Discussion}

\section{Saptial and temporal variations of HPCs}

\section{Urban area impact}

The variation of HPCs load in the river Vilaine in two sites located respectively upstream and downstream from the city of Rennes (211 778 inhabitants in 2008) was studied in four SW samples between February to April 2009. Fig. 4 represents the loads difference between upstream and downstream for each the three groups of HPCs defined above (Fig. 2). The loads difference was calculated in gram per day from the corresponding mean flow rate of the river Vilaine at these two sites. As the river mean flow strongly increased from $1.72 \mathrm{~m}^{3} \mathrm{~s}^{-1}$ upstream versus $14.6 \mathrm{~m}^{3} \mathrm{~s}^{-1}$ downstream, due to one tributary and the treated wastewater discharge (360000 inhabitants equivalents for the WW treatment plant of Rennes area) the impact of dilution appeared to be negligible with regard to the increase of

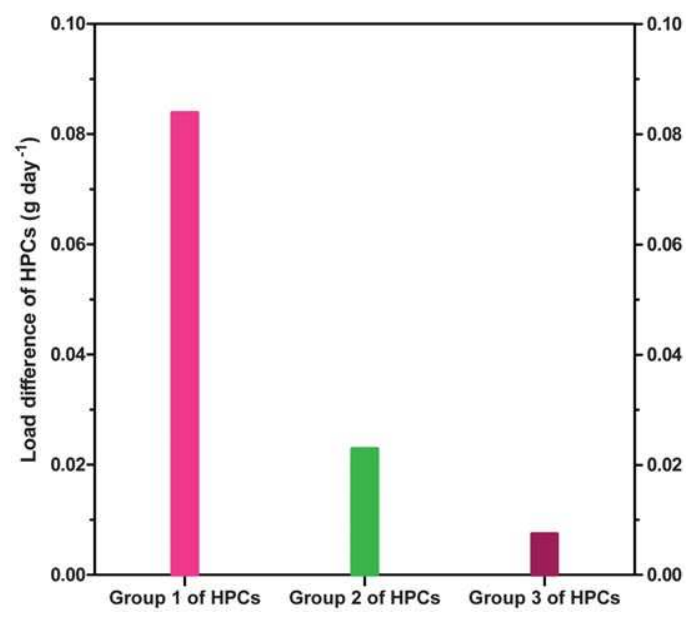

Fig. 4 Load difference for the three groups of HPCs $\left(\mathrm{g} \mathrm{d}^{-1}\right)$ between upstream and downstream from Rennes. 
concentrations. These results may be explained by the high release of HPCs in treated WW in spite of their partial elimination in treatment steps. Moreover, the close correlation between the HPCs occurrence in SW and urban impact has already been reported in the literature..$^{2,6}$

\section{Monthly variation}

Mean HPCs concentrations of each group of HPCs determined above (Fig. 2) varied over the four months of the study, January to April 2009 (Fig. 5). The same general tendency of monthly variations was observed for all three groups over the period excepted for the group 3 between January to February 2009 for which the low mean concentrations remained constant (i.e. $1.3 \mathrm{ng} \mathrm{L}^{-1}$ ).

Mean concentrations of the group 1 to 3 of HPCs generally decreased with a rate of $50 \%, 30 \%$ and $80 \%$ respectively, but less than the mean flow rate $(80 \%)$. Therefore, the general dissipation of HPCs in SW over the investigated period cannot be explained by the fact of dilution in this study. Otherwise, the greater concentrations of HPCs observed in January and February may be due to lower temperatures which may reduce both the biodegradation and the photodegradation of HPCs in SW. ${ }^{32,59}$ Additionally, it may be assumed that the variations of drugs prescription with time during the investigated period, which is correlated to other factors besides the climatic conditions, could also be responsible of the monthly variation observed of HPCs contamination in SW.

However, a surprising increase of mean concentrations for all HPCs groups was observed in March while the mean flow rate decreased dramatically. This could be explained by a heavy

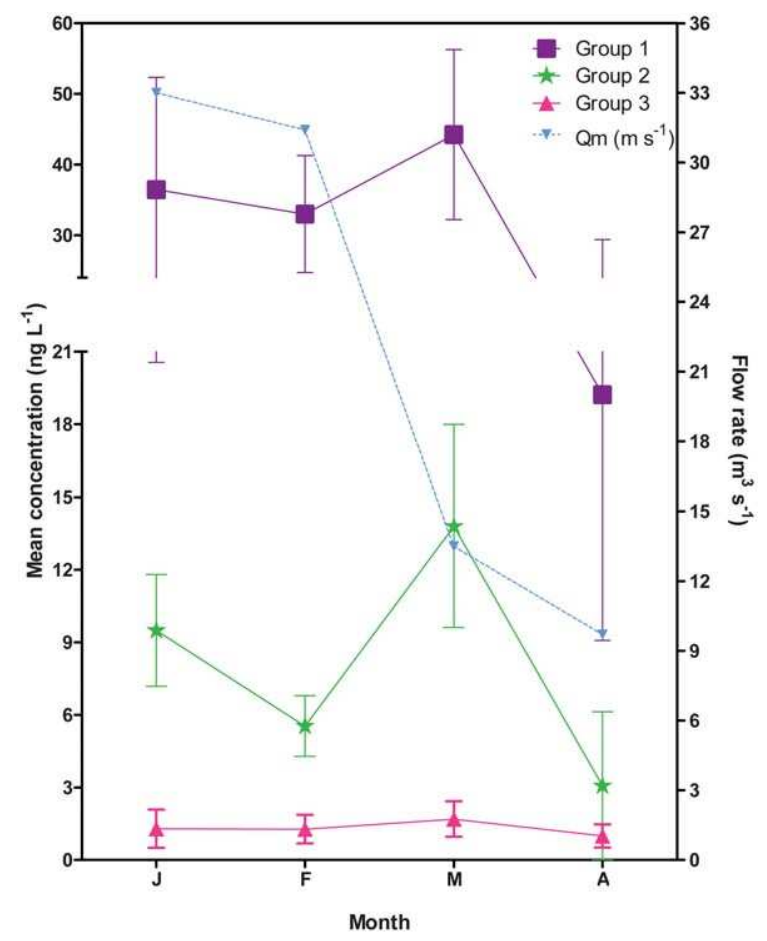

Fig. 5 Monthly variations of HPCs concentration (group 1, 2, and 3) in $\mathrm{ng} \mathrm{L}{ }^{-1}$ in all SW samples between January to April 2009 (bars indicate the standard deviation of mean HPCs concentrations). rainfall event at the beginning of the month $(18.8 \mathrm{~mm}$ in Rennes for the 3 rd of March) with sewage overflows, ${ }^{60}$ contributing to the increase of HPCs concentrations in river. In addition, the possible effect of the weather instability during March (alternating frosty days with relatively hot periods) on the occurrence of human pathologies cannot be dismissed to understand these results because it may contribute to increase drugs prescription. However, the monthly variation results have to be treated with caution because of the difference of the number of analysed samples during each month, the number of SW sampled in March 2009 being more than 2 to 5 times greater than during the other 3 months (26 samples in March versus 8, 13 and 5 samples in January, February and April, respectively).

\section{DW treatments}

The results presented above, in particular the treatment efficiency, do not make it possible to assess the efficiency of each treatment stage. However, the literature can provide some answers. For example, the coagulation step does not seem to be a suitable process for eliminating trace levels of HPCs. ${ }^{9,51,61,63}$ However, Stackelberg et al. ${ }^{9}$ showed moderate removal of SFMZ (nearly 33\%) and ACE (nearly 60\%) after ferric chloride coagulation. Adams et al. $^{61}$ suggested that antibiotics (seven sulfonamides and TRP) may be adsorbed onto suspended colloidal matter in surface water, and may then be removed during clarification.

For adsorption, activated carbon (in powder PAC or grain GAC) is usually used to adsorb the natural organic matter and micropollutants, depending on their Kow coefficient (octanolwater partition coefficient). As organic compounds, such as IOP, have a low Kow $(<4)$ it is thought that they are poorly retained on GAC or PAC. ${ }^{\mathbf{8}, 35}$

Sand-GAC filtration and PAC filtration are commonly used in DW facilities to eliminate a wide range of fine particles (colloids and supracolloids), bacteria and prevent odour and taste in DW. This step can be very efficient with, for example, more than $95 \%$ of CAF and CBZ removed. ${ }^{9}$ In addition, HPCs may be biodegraded, for example during filtration on activated carbon. ${ }^{64}$

Oxidation, with either ozone and/or chlorine, can lead to the degradation of HPCs depending on oxidant doses, contact time, $\mathrm{pH}$, temperature conditions and on the structure and physical and chemical properties of the HPCs. Adams et al. ${ }^{61}$ studied spiked Missouri river water samples and distilled water $\left(0.5 \mathrm{mg} \mathrm{L}^{-1}\right)$ with 7 antibiotics including TRP, and found a 95\% degradation of each HPC $\left(\mathrm{pH}=7.5,0.3 \mathrm{mg} \mathrm{L}^{-1} \mathrm{O}_{3}, \mathrm{t}=1.3 \mathrm{~min}\right)$. Ternes et al. ${ }^{63}$ found more than $97 \%$ degradation for $\mathrm{CBZ}\left(\mathrm{pH}=7.8,0.5 \mathrm{mg} \mathrm{L}^{-1} \mathrm{O}_{3}, \mathrm{t}=\right.$ $20 \mathrm{~min})$, whereas CLO was poorly degraded $(\leq 40 \%)$ even under high $\mathrm{O}_{3}$ concentration (2.5-3 $\mathrm{mg} \mathrm{L}^{-1}$ ). ATE may be degraded by ozone on its amine function ${ }^{50}$ and a complete SFMZ removal was observed in $15 \mathrm{~min}$ with $0.4 \mathrm{~g} \mathrm{~L}^{-1}$ ozone. ${ }^{65,66}$

Chlorination may also produce by-products with unexpected properties. For example, chlorination of ATE could give three by-products with potential phycotoxic activity. ${ }^{67}$ Moreover, natural organic matter (NOM) may interfere during chlorination with a reaction time varying from around $20 \mathrm{~min}$ in distilled water up to $40 \mathrm{~min}$ in SW for a $90 \%$ degradation of antibiotics with $0.1 \mathrm{mg} \mathrm{L}^{-1}$ of $\mathrm{Cl}_{2}{ }^{61}$ 
However, CAF and CBZ are neutral compounds and CLO and IBU are acidic compounds and could resist chlorination. ${ }^{62}$ Chlorination for 200 to $300 \mathrm{~min}$ can lead to a $100 \%$ degradation of SFMZ and ACE but only $8 \%$ and $20 \%$ of CAF and CBZ. ${ }^{9}$

All these findings are consistent with the results for the $11 \mathrm{WUs}$ except for finding HPCs present at very low concentrations only in DW (CIP, FMQ and CLO). Depending on the possible variability in all these treatment process parameters between all the concerned WUs, the occurrence of CIP and FMQ in a few samples may be explained. CLO, the metabolite of clofibrate, was found in this study in SW and DW although clofibrate has not been prescribed in France since 1999. However, its presence in environment could be explained by its persistence in environment and its resistance to chlorination. However, the author observed some difficulties to differentiate CLO from its isomer (mecoprop) which is used as a pesticide in this study area. ${ }^{68}$

\section{Conclusions}

The aim of this paper was to determine the occurrence of widely used human pharmaceutical compounds and metabolites in the surface water and drinking water in Brittany, France. The results demonstrated the ubiquitous presence of 16 of the 20 target HPCs in both surface water and drinking water, at concentrations generally two or three times higher in surface water than in treated water. Some high concentration can be stressed such as $300 \mathrm{ng} \mathrm{L}^{-1}$ for acetaminophen in surface water and $100 \mathrm{ng} \mathrm{L}^{-1}$ for salicylic acid in treated water. Qualitatively, the evaluation of the weighted distribution of HPCs in both surface water and treated water showed that nearly half were psychostimulants (i.e. caffeine and its main metabolite 1.7 dimethylxanthine), the other half being mainly non steroidal anti-inflammatory drugs, iodinated contrast media, anxiolytic drugs, lipid regulators and $\beta$-blockers. Overall, comparing quantitative and qualitative results with the assessment of the removal rate of HPCs for 11 selected WUs with a complete treatment, including clarification, filtration, oxidation processes, the majority of HPCs seemed to be well retained or degraded, by adsorption on activated carbon and oxidation with ozone and/or chlorine. However, psychostimulants and non steroidal anti-inflammatory drugs were not completely removed.

In order to complete the results of this study, further experiments could be carried out during extreme weather events, at least during dry and wet periods, to study the possible effect on water quality of DW resources of concentration at low water level, or of soil leaching or dilution at high water level.

This study helps to provide an assessment, over a large area, of the environmental footprint of HPC contamination from SW to DW, suggesting the need for further research to prioritize HPCs (i.e. resistent HPCs to DW treatment processes) and HPC byproducts to assess the health risk.

\section{Acknowledgements}

The authors wish to thank Michel Garcin and Roger Faverais (ARS Bretagne) for their fruitful discussions and for kindly sharing their experience and information about the DW supplies selected for this study. The authors are also grateful to Aude
Caraës, Claire Arcelin, Mylène Cuart, and Marielle Blot (LERES/EHESP) for the sample analysis.

\section{References}

1 A. L. Spongberg and J. D. Witter, Sci. Total Environ., 2008, 397, 148 157.

2 A. J. Watkinson, E. J. Murby, D. W. Kolpin and S. D. Costanzo, Sci. Total Environ., 2009, 407, 2711-2723.

3 A. C. Alder, C. Schaffner, M. Majewsky, J. r. Klasmeier and K. Fenner, Water Res., 2010, 44, 936-948.

4 S. L. Bartelt-Hunt, D. D. Snow, T. Damon, J. Shockley and K. Hoagland, Environ. Pollut., 2009, 157, 786-791.

5 J. M. Conley, S. J. Symes, M. S. Schorr and S. M. Richards, Chemosphere, 2008, 73, 1178-1187.

6 J. Feitosa-Felizzola and S. Chiron, J. Hydrol., 2009, 364, 50-57.

7 B. Kasprzyk-Hordern, R. Dinsdale and A. Guwy, Anal. Bioanal. Chem., 2008, 391, 1293-1308.

8 S. Mompelat, B. Le Bot and O. Thomas, Environ. Int., 2009, 35, 803814

9 P. E. Stackelberg, J. Gibs, E. T. Furlong, M. T. Meyer, S. D. Zaugg and R. L. Lippincott, Sci. Total Environ., 2007, 377, 255-272.

10 F. Tamtam, F. Mercier, B. Le Bot, J. Eurin, Q. Tuc Dinh, M. Clément and M. Chevreuil, Sci. Total Environ., 2008, 393, 84-95.

11 T. A. Ternes, Water Res., 1998, 32, 3245-3260.

12 Y. Yoon, J. Ryu, J. Oh, B. G. Choi and S. A. Snyder, Sci. Total Environ., 2010, 408, 636-643.

13 C. P. Yu and K. H. Chu, Chemosphere, 2009, 75, 1281-1286.

14 J. L. Zhao, G. G. Ying, L. Wang, J. F. Yang, X. B. Yang, L. H. Yang and X. Li, Sci. Total Environ., 2009, 407, 962-974.

15 I. Robinson, G. Junqua, R. Van Coillie and O. Thomas, Anal. Bioanal. Chem., 2007, 387, 1143-1151.

16 C. Coetsier, L. Lin, B. Roig and E. Touraud, Anal. Bioanal. Chem., 2007, 387, 1163-1166.

17 P. E. Stackelberg, E. T. Furlong, M. T. Meyer, S. D. Zaugg, A. K. Henderson and D. B. Reissman, Sci. Total Environ., 2004, 329, 99-113.

18 N. M. Vieno, H. Harkki, T. Tuhkanen and L. Kronberg, Environ. Sci. Technol., 2007, 41, 5077-5084.

19 R. López-Serna, S. Pérez, A. Ginebreda, M. Petrović and D. Barceló, Talanta, 2010, 83, 410-424.

20 M. J. Benotti, R. A. Trenholm, B. J. Vanderford, J. C. Holady, B. D. Stanford and S. A. Snyder, Environ. Sci. Technol., 2009, 43, 597-603.

21 E. Vulliet, C. Cren-Olivé and M. F. Grenier-Loustalot, Environ. Chem. Lett., 2009, 9, 103-114.

22 T. Heberer, B. Fuhrmann, K. Schmidt-Bäumler, D. Tsipi, V. Koutsouka and A. Hiskia, Fresenius Environ Bull, 1997, 6, 438443.

23 R. Tauber, 2003, http://popups.ctv.ca/content/publish/popups/PDFs/ DrugReportFinal030202.pdf.

24 A. Togola and H. Budzinski, J. Chromatogr., A, 2008, 1177, 150158.

25 A. Putschew, S. Schittko and M. Jekel, J. Chromatogr., A, 2001, 930, 127-134.

26 T. Heberer and H. J. Stan, Vom Wasser, 1996, 86, 19-31.

27 T. Heberer, Ground Water Monit. Rem., 2004, 24, 70-77.

28 H. J. Stan, T. Heberer and M. Linkerhägner, Vom Wasser, 1994, 83, 57-68.

29 M. Stumpf, Vom Wasser, 1996, 86, 291-303.

30 E. Zuccato, D. Calamari, M. Natangelo and R. Fanelli, Lancet, 2000, 355, 1789-1790.

31 G. A. Loraine and M. E. Pettigrove, Environ. Sci. Technol., 2006, 40, 687-695.

32 N. M. Vieno, T. Tuhkanen and L. Kronberg, Environ. Sci. Technol,, 2005, 39, 8220-8226.

33 A. Chevance and G. Moulin, Agence française de sécurité sanitaire des produits de santé, 2008.

$34 \mathrm{~J}$. P. Besse and J. Garric, Médicaments à usage humain: risque d'exposition et effets sur les milieux récepteurs., 2007, pp. 1-241.

35 S. Pérez and D. Barceló, Anal. Bioanal. Chem., 2007, 387, 1235-1246.

36 A. C. Johnson, M. D. Jürgens, R. J. Williams, K. Kümmerer, A. Kortenkamp and J. P. Sumpter, J. Hydrol., 2008, 348, 167-175. 
37 K. Kümmerer and A. Al-Ahmad, Environ. Sci. Pollut. Res., 2010, 17, 486-496.

38 F. Tamtam, F. Mercier, J. 1. Eurin, M. Chevreuil and B. Le Bot, Anal. Bioanal. Chem., 2009, 393, 1709-1718.

39 D. M. Pavlovic, S. Babic, A. J. M. Horvat and M. Kastelan-Macan, TrAC, Trends Anal. Chem., 2007, 26, 1062-1075.

40 M. Huerta-Fontela, M. T. Galceran and F. Ventura, J. Chromatogr., $A, 2011,45,1432-1442$.

41 L. Nováková, L. Matysová and P. Solich, Talanta, 2006, 68, 908-918

42 J. Schappler, R. Nicoli, D. Nguyen, S. Rudaz, J. L. Veuthey and D. Guillarme, Talanta, 2009, 78, 377-387.

43 Guidance for Industry: Bioanalytical Method Validation, U.S Department of Health and Human Services, Food and Drug Administration Centre for Drug Evaluation and Research (CDER), Centre for Veterinary Medicine (CVM), May 2001 BP, http://www. fda.gov/cder/guidance/index.htm, 2004.

44 D. W. Kolpin, E. T. Furlong, M. T. Meyer, E. M. Thurman, S. D. Zaugg, L. B. Barber and H. T. Buxton, Environ. Sci. Technol., 2002, 36, 1202-1211.

45 A. Moffat, M. D. Osselton and B. Widdop, Clarke's Analysis of Drugs and Poisons, 2004, Pharmaceutical Press, London, 3rd edn, 1-2136.

46 M. M. Huber, S. Korhonen, T. A. Ternes and U. von Gunten, Water Res., 2005, 39, 3607-3617.

47 E. Chamberlain and C. Adams, Water Res., 2006, 40, 2517-2526.

48 N. Vieno, T. Tuhkanen and L. Kronberg, Environmental Technology, 2006, 27, 183-192.

49 I. J. Buerge, T. Poiger, M. D. Müller and H. R. Buser, Environ. Sci. Technol., 2003, 37, 691-700.

50 W. Hua, E. R. Bennett and R. J. Letcher, Water Res., 2006, 40, 2259 2266.

51 M. Rabiet, A. Togola, F. Brissaud, J. L. Seidel, H. Budzinski and F. Elbaz-Poulichet, Environ. Sci. Technol., 2006, 40, 5282-5288.

52 I. J. Buerge, H. R. Buser, T. Poiger and M. D. Müller, Environ. Sci. Technol., 2006, 40, 7242-7250.
53 H. Goossens, M. Ferech, R. Vander Stichele and M. Elseviers, Lancet, 2005, 365, 579-587.

54 N. Kemper, Ecol. Indic., 2008, 8, 1-13.

55 E. M. Golet, A. Strehler, A. C. Alder and W. Giger, Anal. Chem., 2002, 74, 5455-5462.

56 J. Tolls, Environ. Sci. Technol., 2001, 35, 3397-3406.

$57 \mathrm{~K}$. Kümmerer, in: Kümmerer K, editor. Pharmaceuticals in the environment, 3rd edn Berlin Heidelberg: Springer-Verlag; 2008, Chapter 6, pp. 75-93.

58 A. L. Boree, W. A. Anold and K. McNeill, Environ. Sci. Technol., 2004, 38, 3933-3940.

59 W. Y. Hua, E. R. Bennett, X.-S. Maio, C. D. Metcalfe and R. J. Letcher, Environ. Toxicol. Chem., 2006, 25, 23562365.

60 I. Delpla, A.-V. Jung, E. Baures, M. Clement and O. Thomas, Environ. Int., 2009, 35, 1225-1233.

61 C. Adams, Y. Wang, K. Loftin and M. Meyer, J. Environ. Eng., 2002, 128, 253-260.

62 D. Löffler, M. Meller, J. Römbke and T. Ternes, Environmental Research of the Federal Ministry of the Environment, Nature Conservation and Nuclear Safety, 2004, 1-148.

63 T. A. Ternes, M. Meisenheimer, D. McDowell, F. Sacher, H. J. Brauch, B. Haist-Gulde, G. Preuss, U. Wilme and N. ZuleiSeibert, Environ. Sci. Technol., 2002, 36, 3855-3863.

64 S. Zuehlke, U. Duennbier and T. Heberer, Chemosphere, 2007, 69, $1673-1680$.

65 R. F. Dantas, S. Contreras, C. Sans and S. Esplugas, J. Hazard. Mater., 2008, 150, 790-794.

66 M. C. Dodd and C. H. Huang, Environ. Sci. Technol., 2004, 38, 56075615.

67 M. DellaGreca, M. R. Iesce, P. Pistillo, L. Previtera and F. Temussi, Chemosphere, 2009, 74, 730-734.

68 H. R. Buser, M. D. Müller and N. Theobald, Environ. Sci. Technol,, 1998, 32, 188-192. 